\title{
Antártida: Infierno blanco. Una aproximación desde la literatura
}

\author{
ANTARCTICA: WHITE HELL. AN APPROACH FROM LITERATURE \\ ANTÁRTICA: INFERNO BRANCO. UMA ABORDAGEM DA LITERATURA
}

\author{
Sebastián Astorga *1 \\ sastorga2@uc.cl
}

\section{Resumen}

Las ficciones literarias sobre territorios desconocidos se remontan a la Antigüedad. Estos espacios vacíos en los mapas han sido fuente de inspiración y proyección de temores y deseos arcaicos. La Antártida es el último territorio en ser descubierto en la Tierra, recién en 1819 se puso pie ahí. En la literatura moderna, la expedición al sur desconocido tiene una rica tradición, donde se mezclan grandes aventuras, horrores y presagios. En esta investigación se revisan cinco textos en los cuales el viaje hacia el continente blanco se imagina como una catábasis-viaje a un infierno-a la vez que una provocación (hybris) al orden universal: "La balada del viejo marinero" (1798) de S. T. Coleridge, La narración de A. G. Pym (1838) de E. A. Poe, La esfinge de los hielos de J. Verne (1897), En las montañas de la locura (1936) de H. P. Lovecraft, y Los conquistadores de la Antártida (1945) del chileno F. Coloane. La lectura comparada de estas obras muestra repeticiones estructurales y simbólicas que dan cuenta de una clave crítica: la potencia de la naturaleza salvaje sobre el registro humano y la catástrofe en que puede desembocar el ánimo de conquista y dominio.

Palabras clave: expedición antártica, catábasis, hybris, naturaleza insurgente, catástrofe

\footnotetext{
Abstract

Literary fictions about unknown territories date back to antiquity, given that these empty spaces on maps have been a source of inspiration and projection of archaic fears and desires. Antarctica was the last territory to be discovered on Earth and it was not until 1819 that human beings set foot there. Therefore, in modern literature, the expedition to the unknown south has a rich tradition, mixing great adventures, horrors, and omens. In this article, I analyze five texts in which the journey to the white continent is imagined as a catabasis-travel to hell-as well as a provocation (hybris) to universal order: "The Rime of the Ancient Mariner" (1798) by ST

$1 *$ Universidad Católica de Chile

Tekoporá ${ }^{\circledR}$. Centro Universitario de la Región Este. Universidad de la República (C) Astorga. (2021)

Este es un artículo de Acceso Abierto distribuido bajo licencia Creative Commons (CC BY NC 4.0)
} 
Coleridge, The Narrative of AG Pym (1838) by EA Poe, The Sphinx of the Ice Fields by J. Verne (1897), At the Mountains of Madness (1936) by HP Lovecraft, and The Conquerors of Antarctica (1945) by the Chilean F. Coloane. A comparative reading of these works shows structural and symbolic repetitions that account for a critical key: the power of wild nature over the human record and the catastrophe to which the spirit of conquest and domination can lead.

Keywords: antarctic expedition, catabasis, hybris, insurgent nature, catastrophe

\title{
Resumo
}

As ficções literárias sobre territórios desconhecidos datam da Antiguidade. Esses espaços vazios nos mapas têm sido uma fonte de inspiração e projeção de medos e desejos arcaicos. A Antártica é o último território a ser descoberto na Terra, somente em 1819 a humanidade pôs os pés lá. Na literatura moderna, a expedição ao desconhecido sul tem uma rica tradição, onde grandes aventuras, horrores $e$ presságios se misturam. Nesta pesquisa, são revisados cinco textos nos quais a viagem ao continente branco é imaginada como uma catabasis -descer ao inferno-, além de uma provocação -hybris- à ordem universal: "A Balada do Velho Marinheiro" (1798) por S. T. Coleridge, A Narrativa de AG Pym (1838) por E. A. Poe, A esfinge do gelo por J. Verne (1897), Nas montanhas da loucura (1936) por H. P. Lovecraft, e Os conquistadores da Antártica (1945) do chileno F. Coloane. Uma leitura comparativa dessas obras mostra repetições estruturais e simbólicas que respondem por uma chave crítica: o poder da natureza selvagem sobre o registro humano e a catástrofe a que o espírito de conquista e dominação pode conduzir.

Palavras-chave: expedição antártica, catabasis, hybris, natureza insurgente, catástrofe

\author{
¿Vivimos dentro de los muros de nuestras ciudades o bajo la \\ bóveda de las constelaciones? ¿En cuál de las dos? ¿Cuál de las dos es \\ más nuestra morada? \\ Michel Serres, El contrato natural (2004, p. 114) \\ La monstruosidad natural se acompaña de una espiritual. \\ Ida Vitale, De plantas y animales (2019, p. 49)
}

\section{Introducción}

Jorge Luis Borges, en su ensayo "La flor de Coleridge" (1952), sostiene dos ideas que son clave para el trabajo que me toca mostrarles: la unidad espiritual de la literatura y el ejercicio imaginario anticipatorio que esta puede practicar. Para ello se sirve de sentencias de P. Valery, R.W. Emerson y P.B. Shelley. Del primero, recoge la conceptualización de que la historia de la literatura no debe entenderse 
como una concatenación de autores, sino como la "historia del Espíritu como productor o consumidor de literatura" (1974, p. 639); del segundo, que los libros son "obra de un solo caballero omnisciente" (p. 639); y del tercero, "que todos los poemas del pasado, del presente y del porvenir, son episodios o fragmentos de un solo poema infinito" (p. 639). Borges evoca este pensamiento para un "modesto propósito" (p. 639), como él dice, que es el de desplegar la evolución de una "antiquísima tradición literaria: la previsión de hechos futuros" (p. 639). La previsión, la anticipación, como hace notar Borges, tiene referentes en las profecías bíblicas, en la Eneida, en las mitologías nórdicas, por nombrar algunos, y se actualiza, como desarrollará, en la obra de Coleridge, de Wells y de W. James.

Para este trabajo, retomo la idea de la existencia de un contínuum poético para pensar un conjunto de obras que imagina el tópico del viaje hacia el sur desconocido, hacia la Terra Incognita, hacia la Antártida, tópico hermano de la tradición literaria de la anticipación, en cuanto imagina lo desconocido y advierte sobre los peligros y maravillas de la aventura. En los textos que aquí presentaré, de diferentes épocas y origen, se repite una advertencia-ecológica avant la lettre, podemos interpretar hoy-en torno a los peligros de explorar los territorios del sur, como último espacio desconocido y salvaje de la Tierra. La perturbación humana de este espacio virgen reactualiza el concepto griego de hybris, como desmesura y afrenta humana hacia el orden de los dioses (Jaeger, 1980, p. 76) y, junto con ello, reinstala el también viejo tópico de la catábasis, del héroe que desciende al Infierno y retorna con una nueva sabiduría (Campbell, 2017, p. 45).

El espacio arquetípico del Infierno como "emplazamiento cósmico" (Bonnefoy, 2010, p. 884) se repite en distintas culturas de modo casi análogo, figurado como un lugar subterráneo, de castigo y habitado por los muertos, donde dominan el mal, el horror, lo demoníaco, la brumosidad y la pérdida de la unidad y de la individualidad, "lo definitivamente inconsistente, es decir, lo monstruoso" (Castelli, 2007, p. 65). Este escenario supervive y reaparece "sintomáticamente" (Didi-Huberman, 2009, p. 26) en la cultura occidental. En la literatura, en particular, se puede rastrear su representación en un canon poético fundamental: la Biblia, los textos homéricos, Virgilio, Dante; figuraciones que alimentan la representación moderna del Infierno, desplazándose muchas veces la topografía subterránea hacia superficies desconocidas e imposibles de habitar: las selvas, los desiertos de arena, de agua y hielo. Así como se ha representado la selva amazónica como un "Infierno verde", la Antártida, como revisaremos aquí, se ha presentado como un Infierno blanco. Dada la potencia biológica y geológica, tanto de la selva como de la Antártida, y la voluntad libresca de exaltar lo macabro (Rueda, 2003, p. 31), se repite una figuración temible, monstruosa, para los sujetos que ahí se aventuran. Esta representación, como decía, hereda elementos míticos y de la tradición clásica sobre el descenso a los infiernos (Morales, 2013, p. 343-360), una atención y fascinación de corte romántico hacia lo sublime natural, así como un importante acento dado por la influyente literatura del imperialismo inglés (Rojo,

\footnotetext{
${ }^{2}$ Inferno verde. Cenas e Cenários do Amazonas (1908) fue como tituló su libro de relatos el brasileño Alberto Rangel (1871-1945), imagen que ha sido retomada por múltiples autores, en particular en la llamada "novela de la selva", siendo la obra más emblemática La vorágine (1924) del colombiano José Eustasio Rivera (1888-1928).
} 
2009, pp. 15-23): de hombres blancos, aventureros occidentales, en lugares exóticos-D. Defoe, R.L. Stevenson, R. Kipling y J. Conrad, entre otros-que, como muestra Mary Louise Pratt (2010), sirvieron para darle un lugar al europeo en partes no europeas del mundo (p. 24).

Trabajaré aquí una articulación literaria que se da prácticamente como una saga poética: desde "La balada del viejo marinero" (1798) de S. T. Coleridge, pasando por La narración de A. G. Pym (1838) de E. A. Poe, La esfinge de los hielos de J. Verne (1897), En las montañas de la locura (1936) de H. P. Lovecraft, para terminar en la novela del chileno Francisco Coloane, Los conquistadores de la Antártida (1945). En todas estas obras se elabora el conflicto del humano ante la naturaleza salvaje, los temores y las advertencias ante el peligro mortal de irrumpir en lo desconocido y virgen, así como las soluciones imaginarias-los referentes simbólicos y literarios-ante la magnitud del espacio por conocer, las que se concatenan de manera ejemplar entre las distintas escrituras. El descenso a lo subterráneo dado en la imaginación clásica sobre el Infierno, en estas obras se figura como un viaje al sur sobre los océanos, por las latitudes del mapa hacia la finis terrae, a un territorio que, como "naturaleza insurgente [...] rechaza activamente el avance del sujeto" (Andermann, 2018, p. 176) y se resistirá a su conquista. El violento conflicto humano-naturaleza que estas obras despliegan da cuenta de manera ejemplar y crítica de las luces y sombras de la ontología occidental: el naturalismo dualista (Descola, 2012, p. 190), la maquinaria antropocéntrica (Agamben, 2016, p. 58) y la tesis de la excepción humana, que marca diferencias dicotómicas entre humanos-la especie elegida desde el Génesis-y otros seres (Schaeffer, 2009, p. 37). Las aventuras en esta saga poética, como veremos, en la inmersión en la naturaleza salvaje, en la materia, en el "drama natural" (Bachelard, 2017, p. 136), resaltan este conflicto ontológico mostrando-hasta la locura y la muerte-sus profundas fisuras, que son las que hoy están expuestas objetiva y catastróficamente en la crisis ambiental global.

La Antártida es el último territorio cartografiado en la Tierra. Recién en 1819 se puso pie en ella, pero la figuración imaginaria sobre esta zona se remonta muy atrás. Como lo estudia Rojas Mix (2015), existía, desde la época de los griegos, la noción de "un mundo exótico, la extera Europae [la cual] flotaba en brumas de incertidumbre, en las que se mezclaba la realidad con el mito" (p. 15). A este ajuste entre mito, fantasía y cartografías de viajeros reales e imaginarios Rojas Mix le denomina "geografía maravillosa" (p. 15). Los confines del mundo, los espacios vacíos de los mapas sirvieron entonces para proyectar todo tipo de fantasías monstruosas y gloriosas. Entre las monstruosas: dragones, gigantes, acéfalos, esciápodos, sirenas, orejones, caníbales, hombres-animales, amazonas, etc.: "Una simbología que asocia los confines del mundo no solo con lo fantástico, sino con el Mal y el Apocalipsis. El fin del mundo geográfico se confunde con el fin del mundo como fin de los tiempos" (p. 15). Por otro lado, entre las fantasías gloriosas abundan los espacios geográficos ideales que motivaron el emprendimiento de las más peligrosas campañas. El Paraíso, Hiperbórea, el Jardín del Edén, la Atlántida, El Dorado, Jauja, La Ciudad de los Césares, son algunos de estos "lugares imaginarios o maravillosos" (pp. 50-65).

Los avances cartográficos fueron desplazando este ignoto núcleo geográfico 
que provoca a la imaginación. Para mediados del siglo XIX, la única terra incognita de la superficie del Orbe es la Antártida. En 1819 los tripulantes rusos del Vostock, los norteamericanos cazadores de focas en la goleta comandada por Nathaniel Brown Palmer, y los británicos, también en busca de focas, dirigidos por Edward Bransfield, son los primeros exploradores en ver y descubrir oficialmente el continente blanco. Enrique Bunster (1951), en su crónica "Descubrimiento de la Antártica”, cuenta que el primero en llegar a este territorio es Brown Palmer, en campaña de cacería de las focas de doble pelo, las cuales habían sido recién exterminadas en los territorios de la isla Juan Fernández, luego cazadas y arrasadas en los archipiélagos del sur de Chile (con la concomitante corrupción, abuso y exterminio de las comunidades indígenas del territorio: alacalufes, onas y yaganes), para llegar así a la Antártida (p. 49-61). El descubrimiento de la Antártida sería, de este modo, resultado de un progresivo exterminio cultural y animal, violencia, muerte y negatividad que marcarán las ficciones de travesías a este continente. $^{3}$

\section{“La balada del viejo marinero" de Samuel Taylor Coleridge}

En 1798, en Inglaterra, un par de décadas antes del descubrimiento de la Antártida y en plena Revolución Industrial, S. T. Coleridge junto a W. Wordsworth publican Baladas líricas, libro que marca un antes y un después en la poesía de habla inglesa, y que se inscribe como punto de inicio del romanticismo inglés. En su primera edición, el primer poema de este libro es "La balada del viejo marinero", el cual, según el mismo Coleridge relata en su Biographia literaria (1817), pertenece al grupo de poemas "sobrenaturales" de las Baladas, del cual él se haría cargo, siendo los poemas que tratasen la "vida ordinaria" esfuerzo de Wordsworth (Díaz, 1987, p. 34). Según Harold Bloom (2003), siguiendo este esquema la obra general de Coleridge se puede comprender en dos conjuntos: el del modo "conversacional" y el del "modo demoniaco" (p. 11), al que pertenece el poema que acá nos ocupa.

"La balada" es un texto fundacional moderno para la visión del sur como espacio de misterio y horror, en el cual se actualizan las visiones míticas y clásicas del Infierno. Este poema nace probablemente inspirado en los viajes de James Cook-quien cruza por primera vez el círculo polar antártico entre 1773 y 1774, desmitificando la inmensidad que se atribuía hasta entonces a Terra Australis (Fernández-Armesto, 2012, p. 426) ${ }^{4}$-y por los relatos de viaje que desde

\footnotetext{
${ }^{3}$ E. Bunster (1951) muestra las dimensiones de esta cacería y la geopolítica global de la época: "en la isla Más Afuera se reunían rebaños de no menos de tres millones de ejemplares. Solían verse entonces hasta veinte barcos norteamericanos, británicos y franceses, cuyas tripulaciones se entregaban a la tarea de darles muerte a garrotazos. En 1801, cierto buque inglés se llevó un cargamento de un millón de pieles. El mercado distribuidor estaba en Cantón, China [...] Los cueros ordinarios eran preferentemente vendidos en Francia, donde se les usaba para confeccionar los morriones de los soldados napoleónicos. Este cuantioso comercio no fue jamás controlado (p. 50). ${ }^{4}$ En el Diario del Capitán Cook se anota: "He completado un recorrido por las latitudes altas del océano Sur, atravesándolo de forma que no quedara ningún espacio donde pudiera haber un continente, a no ser en las cercanías del polo, fuera del alcance de la navegación". Si alguien, añade, "tiene la resolución y la perseverancia de dilucidar esta cuestión avanzando más al sur de lo que yo lo he hecho, no le envidiaré el honor del descubrimiento; pero me atrevo a afirmar que el mundo no
} 
mediados del siglo XVIII en adelante contribuyen, como anota G. Rojo (2009), “con las bases factuales para el posterior florecimiento del relato de aventura, el del periplo del héroe blanco que se arroja al camino en pos de mundos y experiencias excepcionales" (p. 16). Como se destacará, sus imágenes harán eco en distintas escrituras sobre este territorio en los siguientes dos siglos, como en la de E. A. Poe, J. Verne, H. P. Lovecraft y F. Coloane.

En el poema de Coleridge se relata el trágico viaje de una tripulación al Polo Sur, que es construido poéticamente como una catábasis, un descenso al Infierno, siguiendo, como dice Wordsworth (1994) en la "Advertencia" a las Baladas, "el espíritu de los poetas antiguos" (p. 109). Tal como el noveno círculo del Infierno de Dante, Coleridge (2007) describe esta zona como "la tierra del hielo y de los espantosos ruidos, donde no se veía cosa viviente" (p. 21). A este espacio, al mismo "Polo Sur" (p. 19)—como se anota en las acotaciones en prosa que se disponen en los márgenes del poema ${ }^{5}$-fue arrastrado el barco en una "poderosa y tiránica" (p. 19) tormenta, "que golpeó con sus alas atrapadoras; y nos persiguió hacia el sur" (p. 19), según relata el anciano marinero, único sobreviviente de la travesía y antihéroe de este poema.

Una vez en las cercanías del polo, el viejo marinero describe el drama natural de como la nieve, la niebla, el resplandor doloroso del blanco y el crujir del hielo se toman el escenario y envuelven la percepción de los hombres:

Y en medio de las corrientes los acantilados nevados

enviaban un resplandor lúgubre:

ni formas de hombres ni de bestias vimos...

El hielo nos rodeaba.

Había hielo por aquí, había hielo por allí,

había hielo por todas partes:

crujía y gruñía, y rugía y aullaba, como los ruidos que oímos en un desmayo (p. 21). ${ }^{6}$

A la manera del Hades de Homero: bruma e indeterminación; del Infierno de Dante y Virgilio: la extraña sensación como la de ingresar a un sueño. Como en el Infierno bíblico, donde, para los condenados en el fuego, "será el llanto y el crujir de dientes" (Biblia de Jerusalén, Mt 13:42), salvo que aquí el fuego es reemplazado por su materia inversa, el hielo.

En este lúgubre escenario, y en medio de una horrible calma, condena de los navegantes a vela, aparece un albatros, que es signo de vida, de posible cercanía de tierras. El poeta explicita el contrapunto sagrado y bíblico del relato: "a través de la niebla vino; / como si fuera un alma cristiana, / en nombre de Dios le saludamos" (Coleridge, 2007, p. 21). El ave es recibida con "júbilo y hospitalidad" (p. 21), se le

\footnotetext{
obtendrá ningún beneficio de ello" (Citado por Fernández-Armesto en Los conquistadores del horizonte, 2012, p. 426-427).

${ }^{5}$ Estas glosas marginales no aparecen en la edición príncipe de 1798 sino en 1817 cuando lo incorpora el poeta en su libro Hojas sibilinas (Díaz, 1987, p.14).

6 "The ice was here, the ice was there/ The ice was all around:/ It cracked and growled, and roared and howled,/like noises in a swound!// At length did cross an Albatross:/ Through the fog it came;/ As if it had been a Christian soul,/ We hailed it in God's name" (p. 29).
} 
alimenta y esta acompaña a la nave trayendo buena suerte: pronto los hielos se abren permitiendo un curso al barco y los vientos retornan. Nueve días acompaña felizmente el albatros a la tripulación. Sin embargo, y con esto se cierra la primera parte del poema, el viejo marinero sin razón alguna mata al ave con su ballesta. Este es el punto de la hybris, de la desmesura:

Yo había hecho algo diabólico

que les acarrearía desgracia:

pues todos afirmaban que había matado al ave

que hizo que la brisa soplase (p. 25). ${ }^{7}$

El ave en Coleridge es símbolo de lo sagrado, de la gracia de la creación divina como totalidad y unidad: "Reza bien quien bien quiere,/ al hombre, al pájaro y la bestia [...] por que el Dios amado que nos quiere/ creó y amó a todos" escribe Coleridge (pp. 71-73) cerca del final de su poema, dando cuenta, como anota T. Morton (2018), de su intención crítica de "fomentar una democracia radical que trascienda la política de la compasión" (p. 68). La trasgresión de la unidad sagrada, como desarrolla E. Castelli, daría curso a lo demoníaco: "Lo demoníaco es el no ser que se manifiesta como agresión pura: lo trastocado" (p. 65). Si Dios es unidad-en clave de pensamiento ecológico: "la intimidad con el extraño forastero" (Morton, 2018, p. 68)-lo demoníaco y el mal es la dispersión de esta. El anciano marinero es una especie de Judas, afirmando desesperadamente su yo a costa del resto (Bloom, 2003, p. 175). El asesinato debe ser vengado y los elementos y espíritus se harán cargo de ello (Coleridge, 2007, p. 27).

La unidad sagrada se ha roto y con ello se inicia una serie de catástrofes cargada de símbolos místicos y monstruosos. La tripulación ha descendido al Infierno y en venganza decide crucificar al culpable con el ave amarrada a él, con lo que se corona la parte segunda de este poema. En la tercera parte, un esperanzador barco aparece a lo lejos, se les acerca a pesar de no haber ni vientos ni mareas... es un "barco-espectro" (p. 35), con "la muerte y la vida-en-la-muerte" (p. 35) como toda tripulación, los que se juegan a los dados el destino de los hombres: la vida-en-la-muerte es el destino de nuestro héroe, condenado a esa demoníaca situación indeterminada, de espectro viviente. Todo el resto de la tripulación muere. El barco, entonces, sin vientos ni corrientes comienza a navegar hacia el norte, pero el castigo no ha terminado, los ojos de los muertos siguen clavados horriblemente en él. "Hasta que finalmente la maldición es expiada" (p. 57), y el marinero llega a ver el "faro", "la colina", "la iglesia" de su país natal" (p. 59). Suceden entonces las últimas escenas fantásticas:

¡Cada cadáver estaba tieso, sin vida y tieso,

y por la Santa Cruz!,

¡un hombre todo luz, un hombre seráfico

sobre cada cadáver estaba! [...]

¡era una visión celestial!

Eran como señales a la tierra,

\footnotetext{
7 "And I had done a hellish thing,/ And it would work 'em woe:/ For all averred, I had killed the bird/ That made the breeze to blow!" (p. 24).
} 
Cada uno una luz hermosa (p. 61). ${ }^{8}$

Esta es la anábasis, el retorno a la tierra desde el Infierno. El marinero ha pagado sus culpas, ha cumplido su condena, "consigue un estado de purga" (Bloom, 2003, p.12) y las imágenes de luz, de lo celeste y de la belleza vuelven a predominar. La tierra es un Campo Elíseo en contraste con el tártaro-antártico que ha enfrentado. Entonces, un ermitaño viene en su bote al rescate y el barco se hunde como plomo con los cadáveres. El héroe está a salvo, ha vuelto a su tierra. El ermitaño interroga al marinero por los extraordinarios sucesos que le ha tocado ver, y el cuerpo del marinero se retuerce en "terrible agonía", constreñido "a empezar el relato" (Coleridge, 2007, p. 69), lo que será su penitencia en lo que le reste de vida: "viajar de una tierra a otra" (p. 69) e "instruir" (p. 69) a sus oyentes: "Reza bien quien bien quiere, al hombre, al pájaro y a la bestia..." (p. 73).

El orden universal, natural y espiritual, que tiene origen y unidad divina, al tiempo que es grandioso es frágil y pervertible, según la concepción poética desplegada. El viejo marinero ha contado toda su aventura a un joven que entraba a una fiesta, el cual, se dice, despertó "más triste y más sabio" (p. 73) a la mañana siguiente. El ciclo del héroe se ha cumplido: luego de una prodigiosa aventura, retorna a su tierra para transmitir un nuevo y más complejo conocimiento del mundo (Campbell, 2017, p. 45).

\section{La narración de Arthur Gordon Pym de Edgar Allan Poe}

En 1838, cuatro décadas después de la aparición de "La balada del viejo marinero" y bajo su eco, el escritor estadounidense Edgar Allan Poe (1962) publica La narración de Arthur Gordon Pym. Son muchos los encuentros entre estos dos textos, las formas y tópicos reaparecen: nuevamente es el relato de una misteriosa y catastrófica navegación hacia el sur profundo, por una naturaleza sublime e indomeñable, cuya narración en primera persona y con datos geográficos aparentemente objetivos dan un tono de verosimilitud y de cercanía. Reaparece también el relato de naufragios y de un rumbo incontrolado hacia el sur, descendiendo en la representación del globo como si se tratase del descenso a lo inconsciente y al Infierno. Como anota Bruce Chatwin (1987), "Poe, al igual que Coleridge, a quien idolatraba, era aficionado a las expediciones nocturnas, y estaba obsesionado por el Lejano Sur y por los viajes de aniquilación y renacimiento" (p. 152).

Poe coloca en voz de su protagonista, Pym, el deseo de claros tintes románticos de lanzarse al mar, romper los confines y conocer sobre todo el lado salvaje y oscuro de la naturaleza y del ser humano. Al iniciar la novela, luego de relatar Pym un accidente marino que lo lleva al borde de la muerte, declara la obsesión que lo domina: "nunca experimenté un deseo más ardiente por las violentas aventuras que agitan la vida de un navegante que una semana después de nuestra milagrosa salvación" (p. 114). En la transgresión de la naturaleza es posible

\footnotetext{
8 "Each corse lay flat, lifeless and flat,/ And, by the holy rood" / A mana all light, a seraph-man/ On every corse there stood. [...] It was a heavenly sight!/ They stood as signals to the land,/ Each one a lovely light" (p. 60).
} 
explorar el misterio de la muerte, parece decirnos Poe. De este modo, la travesía de Pym al sur se inicia como polizonte, encerrado en una caja en la bodega de la nave, "sepultado" (p. 122), donde pierde la noción del tiempo, entrando a un espacio onírico. Es la partida del viaje, como la de Dante y del marinero de Coleridge: el héroe pasa el umbral de la vida como forma de "autoaniquilación" para un posible pronto renacer (Campbell, 2017, p. 108).

En el mar vive embocadas y naufragios, quedará a la deriva en un barco a punto de hundirse desde el cual verá pasar, como esperanza de salvación, a un barco lleno de cadáveres, tal cual "La balada" de Coleridge. Lo acecharán tiburones enormes; practicará el canibalismo como único medio de sobrevivencia, y, junto a su amigo Dick Peters, serán finalmente rescatados por la goleta inglesa Jane Guy, a cargo del capitán Guy, que había zarpado con treinta y siete hombres hacia los mares del sur en pos de la cacería de focas. El capitán Guy tiene la intención de dirigirse los más cerca del polo, si el clima lo hace posible (Poe, 1962, p. 260). El 1 de enero de 1828, anota Pym: "nos encontramos por completo rodeados de hielo, y nuestras perspectivas eran, en verdad, muy tristes" (p. 267). Dos semanas después siguen rumbo al sur y el mar se ha abierto. El 19 de enero la goleta arriba a las costas de Tsalal, donde todo es de color negro. Pronto se les acercan en balsas una centena de "salvajes" (p. 276). "Era evidente por entero", dice el narrador, "que no habían visto nunca seres de la raza blanca, cuyo cutis parecía, en realidad, repugnarles" (p. 278). ${ }^{9}$ La tripulación baja a tierra y es invitada a una expedición por la isla, en la cual los indígenas han preparado una fantástica trampa. En camino por unos promontorios, un derrumbe los mata a todos, salvo a Pym y a Peters que se han refugiado en una cueva. G. Bachelard (2017) destaca el nivel cósmico de la trampa narrada por Poe, y con ello su exploración poética de la naturaleza y del mal:

La emboscada tendrá las formas y los medios de un cataclismo universal. Los indígenas desdeñarán servirse de sus armas; practicarán el asesinato mediante los elementos, mediante el derrumbe de tierras amontonadas. El ensueño de E. A. Poe totaliza la maldad de los hombres y la maldad del universo (p. 144).

Pym y Peters logran escapar de la isla en una balsa, tomando de prisionero al indígena $\mathrm{Nu}-\mathrm{Nu}$. En el mar, en este último viaje, son llevados nuevamente al sur por las corrientes. El indígena percibe y sufre los horrores en este blanco infinito. Las aguas se templan, se ponen lechosas, y un temible ambiente de fuerte luminosidad y silencio se toma la escena. "Varios fenómenos nos indicaron entonces que entrábamos en una región de novedad y de sorpresa" (Poe, 1962, p. 331). Las imágenes oníricas e infernales se suceden. Relata Pym: "Sentía un entumecimiento [sic] de cuerpo y de espíritu-una sensación de trasoñar" (p. 334), un estado límite entre lo onírico y la vigilia, en el que lo inconsciente casi sin trabas se toma el espacio perceptivo. Tras días de deriva, lo onírico ocupa lo real. Masas de agua sin sonido, vapor y tinieblas atravesadas por una intensa luz difuminan todo espacio y cosa. Estamos más cerca de la alucinación que de la percepción, y así la balsa es llevada hasta una misteriosa catarata que cae del cielo. La oscuridad

\footnotetext{
9 "Poe era un perfecto racista virginiano" - nos recuerda B. Chatwin-y los negros tsalalinos representan "el colmo de la bestialidad y la astucia vil" (1987, p. 153).
} 
domina el fondo en contraste con esta cortina blanca. Enormes pájaros blancos lívidos vuelan detrás de este velo y chillan “iTekeli-li!” (mismo grito de espanto que los nativos de la isla Tsalal emitían horrorizados por lo blanco). Ante este chillido $\mathrm{Nu}-\mathrm{Nu}$ muere de horror (p. 336). La barca se precipita en los brazos de la catarata "donde se abrió un abismo para recibirnos" (p. 336), de la que emerge y los abraza una esfinge, un gigante blanco amortajado, un misterioso monstruo similar a la figura seráfica y toda luz de Coleridge. Tanto en Poe como en Coleridge es un umbral, de anábasis, de retorno o cierre. El relato de Pym se interrumpe en la siguiente frase: "Y el tono de la piel de la figura tenía la blancura perfecta de la nieve..." (p. 336).

"Monstruo" etimológicamente viene de "mostrar" (monstrare) y "advertir" (monere) (Punter y Byron 2005, p. 263). La esfinge es un punto límite de conocimiento, donde es posible fallecer o seguir el viaje, linde que estos textos sitúan en los desconocidos y deslumbrantes hielos del fin del mundo.

\section{La esfinge de los hielos de Jules Verne}

Siguiendo con la ruta trazada por Coleridge y Poe, en 1897 Jules Verne, el célebre novelista francés, publica La esfinge de los hielos, que dedica al propio E. A. Poe. Desde el comienzo de la narración se sitúan los significantes del sur en la línea de descenso al Infierno que aquí se estudia. El libro de Verne comienza con su protagonista, el científico estadounidense Joerling, narrando desde las Islas de la Desolación. La toponimia no es casual: "Para el comienzo de estas maravillosas y terribles aventuras, sería difícil dar con lugar más apropiado... Diciendo Islas de la Desolación, está dicho todo" (p. 7). Como en Poe, nuevamente y acentuando la verosimilitud, la forma usada por el autor es la del diario de viaje, del relato en primera persona de su protagonista. Joerling se embarca en la goleta Halbrane, y en un juego intertextual su tripulación sigue las huellas de Pym hacia el sur en busca de posibles sobrevivientes de la Jane Guy, la embarcación de la novela de Poe que recaló y fue destruida en la isla Tsalal hace unos once años, como se anota en el libro de Verne (p. 53).

La Halbrane, luego de seis meses de abandonar las Islas de la Desolación, al descender las latitudes naufraga en los flancos de una montaña de hielo. Ante el naufragio, el contramaestre llega a una conclusión que explicita la hybris: "Que no es permitido aventurarse tan lejos en estas regiones (...) el Creador prohíbe a sus criaturas encaramarse a los Polos de la Tierra" (p. 286). Embarcados en un rústico bote, el grupo principal de la tripulación es arrastrado por una fuerte corriente que los lleva hasta la misma esfinge de Pym. Aquí se encuentra la clave poética con que Verne se diferencia de sus antecesores: el novelista francés, por medio de sus héroes, propone una interpretación científica, racionalista, del fenómeno que en Poe era misterio, ensoñación o delirio. En el libro de Verne, la esfinge de los hielos es descubierta como un centro magnético natural de inigualable fuerza. Pero, ¿qué es de los misteriosos testimonios de Pym?, y ¿por qué les ha sucedido a ellos también tan extraordinarios eventos?, se preguntan los héroes de este relato. Especula entonces el capitán, dando espacio al misterio: “¿Qué falta de razón hay en admitir la intervención de un poder sobrenatural en las más ordinarias 
circunstancias de la vida?" (p. 136), a lo que Joerling afirma: "Todos los hechos están unidos por un lazo. Forman una cadena" (p. 136).

Este contínuum, sea natural, sobrenatural, histórico, mitopoético o espiritual-tal como defendía Borges en "La flor de Coleridge"-impulsa explícitamente el plan novelístico de este relato, al mismo tiempo que es constantemente puesto en tensión por la incredulidad racional, por la que parece jugársela Verne en este libro. Las magníficas visiones poéticas que cierran el libro de Poe, develadas como un centro magnético por los héroes de Verne son, para el lector, decepcionantes. La esfinge de los hielos, siguiendo el método analítico de Bachelard, se centra en el drama de las aventuras humanas y en las explicaciones verosímiles y racionalistas de lo que en cambio en Poe, así como en Coleridge, es profunda imaginación material y poética.

Al cerrar esta novela, el narrador reflexiona sobre los avances del conocimiento humano en torno a la naturaleza virgen, marcando un posicionamiento de optimismo científico ante las aventuras que le ha tocado experimentar:

Si los azares y las necesidades de la navegación nos llevaron hasta el Polo Sur, más lejos del punto al que nuestros predecesores llegaron, si hasta pasamos el eje del globo terrestre, no es menos cierto que muchos descubrimientos de incalculable valor quedan aún por hacer en tales parajes. Arthur Gordon Pym, el héroe tan brillantemente narrado por Edgar Allan Poe, mostró el camino... ¡Síganle otros y arranquen a la Esfinge de los Hielos los secretos que conserva del misterioso Antártico! (p. 382).

Como se sabe, la Esfinge es un ser fabuloso antiguo, presentado en la mitología griega como un monstruo mezcla de humano y de distintas especies de animales, el cual, ubicado en una montaña de Tebas devoraba a los viajeros que no eran capaces de responder a sus enigmas. Solamente Edipo pudo resolver la incógnita planteada, con lo que el monstruo se suicida (Grimal, 1989, p. 147b). J. Verne recupera la noción de este monstruo como un paso enigmático, tanto para leer a Poe como para interpretar y celebrar el propio avance científico, entendido como un sobrepasar los misterios de la naturaleza; sin embargo, como desarrolla R. Argullol (2008), el misterio siempre se renueva y se hace más profundo: a Edipo aún le queda conocer su verdad, más mistérica y trágica que su conocimiento objetivo anterior (p. 17), y es en esta "zona de oscuridad", en el "enigma", en la "experiencia inefable", en las "preguntas sin respuesta" donde se puede producir "la verdadera ruptura ontológica" (p. 9) que evita los dogmatismos y permite que se despliegue la aventura. Las fábulas que aquí se presentan plantean la pregunta por las posibilidades y límites del conocimiento de la naturaleza, presentándose esta siempre imposible de ser clausurada, pagando con la muerte o la locura los intentos de rasgar el velo de Isis.

\section{Las montañas de la locura de H. P. Lovecraft}

H. P. Lovecraft retoma estas rutas en Las montañas de la locura, torciendo por completo la confianza en el progreso del conocimiento científico que J. Verne 
expone en la voz de su protagonista. La novela de Lovecraft fue publicada en 1936. Para esos años ya naufragó, aplastada por los hielos, la famosa expedición de E. Schakleton (1915) con la que pretendía atravesar el continente antártico, de norte a sur, pasando por el Polo; ya aconteció la Gran Guerra y los aviones sobrevuelan el Globo conquistándose, como lo desarrolla C. Smith (2019), un "nuevo estadio de la Revolución Espacial (...) una tercera dimensión que viene a añadirse a mar y tierra" (p. 108-111): el aire. En 1930, S. Freud (1994) publica El malestar en la cultura, entre sus páginas anota lo siguiente: "Hoy los seres humanos han llevado tan adelante su dominio sobre las fuerzas de la naturaleza que con su auxilio les resultará fácil exterminarse unos a otros hasta el último hombre” (p. 140).

Nuevamente, como en Poe y Verne, en Las montañas de la locura se juega con la realidad objetiva, testimonial y científica: el libro de Lovecraft se plantea como un informe de los horrores vistos por un grupo de científicos expedicionarios en la gran Meseta Antártica. Como subraya M. Houellebecq (2006) en su libro dedicado al estadounidense:

El estilo de informe científico que utiliza Lovecraft [...] obedece al siguiente principio: cuanto más monstruosos e inconcebibles sean los acontecimientos y entidades descritos, más precisa y clínica ha de ser la descripción. Para diseccionar lo innombrable, se necesita un escalpelo (p. 43).

Este informe dispuesto por Lovecraft en voz de su protagonista se escribe con el objetivo de advertir a la comunidad científica del gran error que puede significar perturbar el territorio antártico. Relata el narrador-protagonista:

Me veo precisado a hablar porque los hombres de ciencia se han negado a seguir mi consejo sin saber la razón. Voy completamente en contra de mis deseos al revelar los motivos que tengo para oponerme a esta proyectada invasión del Antártico-con su inmensa cacería de fósiles y sus horadaciones y licuaciones en escala gigantesca de los antiguos casquetes helados-y me siento tanto más reacio a hacerlo cuanto que mi advertencia puede caer en el vacío (p. 7).

Es notable cómo se adelanta Lovecraft al actual y catastrófico derretimiento de los polos. La puesta en cuestión de la Civilización Industrial, del racionalismo, el cientificismo y el afán de progreso, para los años treinta no era ninguna novedad, pero el calentamiento global aún no era un problema de agenda mundial, por decirlo de algún modo, y el conocimiento sobre la disminución de las masas heladas de los polos no captó la atención hasta los años setenta, con el desarrollo de la fotografía satelital. Recién en junio de 1972, en Estocolmo, se realizó el primer encuentro internacional de naciones para tratar el problema del clima como una cuestión de incumbencia global. Su título es sintomático en su antropocentrismo: "La Conferencia de las Naciones Unidas sobre el Medio Humano". Sin embargo, y a pesar de su tardío aparecer y el foco principalmente humano, es un avance político fundamental, "la jugada maestra", como dice Fernando Estenssoro (2014) en su Historia del debate ambiental en la política mundial 1945-1992, "que permitió la mundialización del debate ambiental hasta llegar, en la última década del siglo XX, a instalarse como una variable fundamental 
e ineludible de la agenda política global, regional y local" (pp. 51-52). El Informe de la conferencia (1973) hace referencia al calentamiento global y a la gravedad para los ecosistemas de la toxicidad industrial, que puede llegar a ser irreparable. El futuro distópico que se dibuja en el Informe, en su forma, tono y contenido, dista poco del previsto por el héroe de la novela de Lovecraft. Y así, lo que era potencia enigmática y sugerente en los tiempos del escritor de Rhode Island, hoy en día sería crudo realismo y denuncia.

Lovecraft en su novela es insistente en fijar esta advertencia al peligro de la investigación antártica, quedando claro, sin embargo, que no será posible disuadir la ambición de conocimiento:

Desde el primer momento, debimos de saber que la curiosidad humana es imperecedera, y que los resultados que anunciábamos bastarían para impulsar a otros en la misma búsqueda milenaria de lo desconocido [...]. Pero ahora se está preparando esa expedición [...]. Si no se les disuade, llegarán al núcleo recóndito del Antártico y derretirán y perforarán hasta sacar lo que sabemos que es capaz de destruir al mundo (p. 64).

El narrador-protagonista espera que los datos que entrega sean sopesados "por sus méritos horriblemente convincentes o a la luz de ciertos ciclos míticos primordiales latamente desconcertantes" (p. 8), y con ello se detengan las expediciones científicas que se están fraguando. Los monstruos encontrados por su expedición, primero como fósiles, luego como horrorosas figuras vivientes, no tienen antecedente terrestre, $y$, se expone, pueden evocar mitos primitivos como el de la Atlántida y otros de la propia cosecha de Lovecraft, como "el pavoroso Necrocomium" (p. 14). Mitología, ficción y ciencia, pues, se entrelazan en este libro, y en este encadenamiento de textos sobre la catábasis y la Antártida. ${ }^{10}$

Como en el mito de Prometeo, develar los secretos es una afrenta a los dioses y el castigo es eterno. Para el Catecismo de la Iglesia Católica (1997), la noción de Infierno en las Escrituras, "son un llamamiento a la responsabilidad con la que el hombre debe usar de su libertad en relación con su destino eterno" (p. 1036). La advertencia del puritano Lovecraft, como la de sus antecesores, se puede leer con todo esto en clave ecológica: la pulsión científica de conocer y dominar puede conllevar la destrucción del objeto y del propio sujeto cognoscente. Es un mensaje conservador o conservacionista, si se quiere, cincuenta años antes del desastre de Chernóbil. La hybris es lo contrario a la prudencia. Anota Houellebecq (2006) en su H.P. Lovecraft: "Los escritores de literatura fantástica son, por regla general, reaccionarios, por la sencilla razón de que son especial, podríamos decir profesionalmente, conscientes de la existencia del Mal” (p. 68).

Cerca del fin de la aventura narrada por Lovecraft, cuando los investigadores ya están por huir del laberíntico palacio subterráneo al que accedieron, de los antiquísimos y monstruosos seres que ahí se encontraron, una "odiosa bruma pálida" (p. 168) avanza hacia ellos, quedan paralizados hasta que un

\footnotetext{
${ }^{10}$ En este mismo horizonte, John Carpenter en 1982 estrena The Thing, película de horror donde un monstruo extraterrestre se les aparece a expedicionarios en la Antártida. Carpenter se basó en la novela Who Goes There? (1938) de John W. Campbell Jr.
} 
sonido los despierta, y escapan despavoridos. El sonido es el siniestro “ ¡Tekeli-lí! ¡Tekeli-lí!” que se escuchaba en las cercanías del Polo Sur en la Narración de A. G. Pym. La bruma del Infierno clásico de Homero y Dante, la bruma que aparece en los escritos de Coleridge, Poe y Verne, se repite aquí, junto a ese sonido siniestro de ave que los despierta, remontándonos, siguiendo la tesis de Borges (1974) sobre la Narración de A. G. Pym, a la unidad fatídica de lo blanco y la muerte (p. 229). Hacia el cierre de la novela de Lovecraft, Danforth, uno de los sobrevivientes de la expedición, enfermo y delirando, como un autómata repite palabras como alternativas siniestras para nombrar el Infierno: "el pozo negro", "la blanca jalea primigenia”, "lo original, lo eterno, lo que no muere” y “iTekeli-lí! ¡Tekeli-lí!” (pp. 184-185).

\section{Los conquistadores de la Antártica de Francisco Coloane}

El chileno Francisco Coloane publica en 1945 Los conquistadores de la Antártica. Escrito en clave realista, su relato se encuentra en el marco histórico de las exploraciones nacionales en la Antártica, con el fin de instalar bases de posicionamiento geopolítico, catorce años antes de la firma del Tratado Antártico (1959), el cual "congeló" la disputa territorial y acordó relaciones pacíficas, de colaboración científica y cuidado medioambiental inéditas en otro territorio del planeta. $^{11}$

En 1947, Chile realiza la primera expedición oficial al territorio Antártico, en la que se funda la base "Soberanía": nuevamente la toponimia no es casual. La travesía se realizó en dos embarcaciones, el Transporte Angamos y la Fragata Iquique, ambas remanentes de la Segunda Guerra Mundial. A bordo del Angamos iba una tripulación de científicos e intelectuales, entre ellos el historiador Eugenio Orrego Vicuña, que luego publicará Terra Australis. Diario de la primera expedición Antártica Chilena (1948); el escritor Enrique Bunster, que también en 1948 publica Corresponsal de la Antártica; y Francisco Coloane. La campaña antártica chilena tuvo gran revuelo mediático, a lo que Gabriela Mistral (1978) llamó con ironía en un artículo: "la Antártida-vedette del año 47" (p. 373). Mistral da cuenta que los pueblos originarios del sur de América, "remeros libres", tenían viejas relaciones, de "costumbre" (p. 374), de "posesión efectiva" (p. 375), con este continente, sin aspavientos publicitarios de "descubrimiento" (p. 375) y conquista, como tanto se celebró en la época; adelantándose con esta diatriba medio siglo a la crítica general en torno a la celebración del V centenario del "descubrimiento" de América. ${ }^{12}$ En 1948 se realizó la segunda campaña nacional al territorio, encabezada por el

11 El Tratado Antártico fue firmado en Washington en 1959, en principio por doce naciones (entre ellas Chile, Argentina, EE. UU, Reino Unido y la URSS) y luego extendido a todos los miembros de la Organización de las Naciones Unidas. En él se establecen, como asuntos principales, su "uso" con fines pacíficos, la cooperación científica internacional para "los intereses de la ciencia y el progreso de toda la humanidad", la prohibición de toda explotación nuclear o de eliminación de desechos radioactivos y la protección medioambiental (María y Delgado, 1999, p. 45-60).

${ }^{12}$ En el marco de dicha celebración, se realizó la Exposición Universal de Sevilla, conocida como Expo 92. Chile participó, con no poca polémica por el gasto y el disparate ecológico, llevando desde la Antártica un iceberg de 60 toneladas. 
presidente Gabriel González Videla, mundialmente el primer presidente en pisar territorio antártico. En esta segunda expedición viaja el escritor chileno filonazi Miguel Serrano, que luego publica La Antártica y otros mitos (1948) y Quién llama en los hielos (1957), ambos con una visión mística del encuentro con lo blanco y lo desconocido.

En estos años, como se muestra, la preocupación por la Antártica es un tema relevante, cultural y políticamente, atravesado por la inminente Guerra Fría. En este contexto, y adelantándose a la propia expedición chilena, Coloane publica Los conquistadores de la Antártica, que, como se analizará, más allá de los valores del coraje y el amor por la aventura, propios de la proeza de estas campañas, relata el sinsentido de la idea de conquista en una naturaleza que se muestra indomeñable e insurgente, y da cuenta, haciendo eco de las ideas de G. Mistral mencionadas, de la posibilidad de una sabiduría del habitar que sea armónica al espacio natural, sin la búsqueda de acumulación ni de provecho material, ideas que se personificarán en la novela en la pareja de una mujer yagana y su compañero disidente de la ciudad.

El primer capítulo del libro se titula, significativamente, "S.O.S.", la señal internacional de auxilio, que en el relato es recibida en la radioestación de Walaia de la Marina de Chile, "situada en uno de los parajes más agrestes, solitarios y australes del mundo: en la desembocadura de la Angostura Murray, frente al Cabo de Hornos" (Coloane, 1966, p. 10). Las primeras líneas de la novela ponen como eje el drama natural, las fuerzas de la naturaleza y su primacía frente al individuo, relación que acompañará el relato completo: "Los relámpagos cruzaban sus bandazos de luz sobre la caseta de la radioestación de Walaia (...) Un trueno retumbó como si desde el confín viniera desmoronándose una gigantesca ruma de tablas, y pasó de largo, con un vaivén sonoro, hacia otro confín lejano" (p. 9). En medio de estas dos imágenes se encuentran, en este paraje salvaje, dos operarios recibiendo desde el mar el mensaje de auxilio. Un rayo destroza la antena y la comunicación se corta. “¡Parecía que las enfurecidas fuerzas atmosféricas hubiéranse concentrado en ese punto de la tierra para herirla y despedazarla!" (p. 12). El agreste lugar en el que se hayan es referido como un gran animal herido, difuminando el escritor con estas marcas las distancia entre lo animado y lo inanimado (p. 12).

Coloane, página a página va instalando marcas de la desigual fuerza entre la naturaleza salvaje y lo doméstico, cuestión que determinará el eje central de este relato, que es la campaña Antártica. La señal de auxilio venía de un barco en peligro de naufragio en el Cabo de Hornos- "El lugar más malo de toda la Tierra” (p. 13), dice un personaje-el cual estaba "como una astilla flotando en medio de esa fiera inmensidad" (p. 25). El ser humano con su tecnología es, de este modo, una pequeña pieza en la inmensidad natural. En el tercer capítulo, se presenta la barca Agamaca con la que se realizará la expedición antártica. Su nombre viene de la cultura yagana y su mitología es un subtexto mitopoético que empezará a tensionar la narración de Coloane, en cuanto a dos modos contrapuestos de habitar la naturaleza (como lo planteábamos con G. Mistral): "Este era el Agamaca, digno del nombre que llevaba: el de la legendaria laguna en la cual después de un diluvio se salvaron las tres canoas de yaganes que volvieron a repoblar esa parte de la tierra que colinda con la Antártida" (p. 30). Estos yaganes, se cuenta más adelante, se 
salvaron comiendo de una ballena que había quedado varada ahí luego de un diluvio (p. 63). Coloane dispone y marca la unidad mítica entre humanos y no-humanos que permea a la comunidad yagana, en la cual predomina un biocentrismo, un contínuum entre especies, lo que, siguiendo las tesis del antropólogo P. Descola (2012), establece una identificación de los humanos con la otredad natural y por tanto un respeto y cuidado en sus relaciones (p. 25-65). El yagán, como narra Coloane, es conocedor de verdades no accesibles a la simple observación, donde los conocimientos de lo natural coinciden con lo poético y lo mítico, lo que los llevaría a una continuidad vital armoniosa entre los elementos.

El Agamaca lo pilotea el indio Félix y en una de sus navegaciones descubre la goleta del pirata Geban que va cargada de pieles, carne y animales robados al viejo Cauquenes, personaje clave de la novela, al ser una especie de reservorio moral en las pillerías de piratas y de conquista que se narran. Cauquenes vive muy al sur con una indígena yagana, y no se sabe bien si es argentino o chileno, "no tenía patria ni bandera" (Coloane, 1966, p. 41), se nos dice. La larga, detallada y sensible descripción que hace Coloane del espacio natural y doméstico de Cauquenes y su mujer, donde muestra la belleza y armonía con la naturaleza de su humilde forma de vida, da cuenta del interés puesto por el escritor en resaltar este espacio, como contraste a los deseos humanos de conquista, nacionalistas o de irracional acción civilizatoria. En la caverna de Cauquenes, se dice, "había tal armonía entre la mano del hombre y de la de la naturaleza, que no se distinguía dónde terminaba la una y comenzaba la otra" (p. 43); y en la descripción de su habla, marcando la corta o nula distancia entre lo humano y lo no-humano, se anota: "Del seno de la tierra parecía manar la voz de ese hombre, encorvado por los años y moldeado en ese hueco de la montaña por los dos únicos elementos que fueron penetrando en su ser a través de la soledad: la piedra y el agua" (p. 47). Esta ética del silencio y de la armonía con el medio natural, de la "hospitalidad esencial" (Argullol, 2008, p. 39), Coloane la hace contrastar con la heroica y ruidosa empresa de la conquista de la Antártida y de las pillerías y aventuras de los hombres que andan de paso por la Patagonia.

Como en los libros antes referidos de viajes al sur a modo de catábasis, el de Coloane también redundará en misterio y tragedia. Primero, ya rumbo a la Antártida, el jefe de la expedición se divierte pescando y recoge un extraño pez con una cabeza que lo hace pensar en algo diabólico, con ojos de "una vaga e inquietante expresión humana" (Coloane, 1966, p.76). El Jefe cuelga a este "monstruo" del palo mayor para mostrárselo a sus compañeros. Una vez que ha amanecido, Félix, el tripulante yagán, queda estupefacto ante tal animal: “abrió desmesuradamente los ojos, y sin mediar palabra, preso de un raro arrebato, corrió hasta el palo, descolgó al pez y lo lanzó al mar, con un gesto en que se mezclaban la repulsión y el horror" (p. 78-79) y les anuncia a sus compañeros: “iMalo, malo, muy malo! ¡Desgracia!” (p. 79), como si del asesinato del albatros de la "Balada” de Coleridge se tratase. Luego de ello, efectivamente la desgracia se instala en esta campaña. Pronto la expedición se sumerge en el sublime y peligroso paisaje, las descripciones nos ponen en línea con las imágenes de catábasis que ofrece Coleridge, Poe y Verne, donde encanto, hermosura y horror se entremezclan:

[J]amás imaginaron un paisaje de semejante soledad y grandeza. 
¡Desolación y blancura por todas partes; pero una desolación y una blancura de tal infinitud y magnificencia, que atraían con poderosa sugestión! El paisaje era fascinante, omnipresente. La luz se descomponía en múltiples colores entre los cristales del hielo y las fantasmagorías más impresionantes se producían entre el cielo y el casquete. El sol lejano parecía no pertenecer a ese paisaje (p. 109).

La omnipotencia de la naturaleza los envuelve y fascina, los atrae magnéticamente. Ese sol lejano podría leerse como un nuevo anticipo de la muerte. Los hielos se estrechan sobre el Agamaca, no es posible huir. El cúter es aplastado por los témpanos hasta naufragar, tal como la famosa expedición del Endurance de Shackleton. Bajan entonces lo indispensable a los hielos y se montan sobre un trineo: “Todos iban silenciosos. El indio Félix lloraba” (p. 114).

El relato se precipita. Dos de los hombres, los únicos sobrevivientes, a camino por el "blanco infinito" (p. 118), llegan famélicos al puesto de unos balleneros noruegos. Una vez recuperados cuentan su historia. Félix, el yagán, como en el relato de Poe, fue el primero en morir. Tanto Poe como Coloane, como se expresa en los textos aquí recogidos, dan a los nativos una especial sensibilidad, intuición e imbricación con las fuerzas naturales, siendo ellos los primeros en percibir la hybris y en morir una vez atravesado el límite de lo posible: desafiando la separación naturaleza y cultura hegemónicas, ellos portan la sensibilidad a lo no humano (Heffes, 2014, pp. 29-30). El segundo en morir es un hombre blanco, el sargento Ulloa, luego de caer "en una especie de locura" (Coloane, 1966, p. 117). Cuenta el narrador:

Entre sus enseres conservó siempre una bandera que pensaba clavar en el Polo mismo en nombre de la patria. Hasta que un día, creyendo haber dado cima a su sueño, la clavó en lo alto de un promontorio, del cual no se supo si resbaló o se arrojó a un escarpado precipicio. Murió al pie de la bandera de su Chile austral (p. 117).

La empresa nacionalista termina así en una muerte absurda.

Para cerrar su novela, en el último capítulo, Coloane esquemáticamente dispone una recuperación del orden y del triunfo del bien sobre el mal: El pirata Geban es encarcelado y se declara que todos los animales por él robados son de Cauquenes. Pero Cauquenes ya está muerto. Fueron a su cueva y ahí estaba su cuerpo sereno e inerte, y una nota en la que dice que su mujer ya está sepultada donde él morirá. También dice la nota que, si se llegase a hacer justicia con sus animales, que estos sean dados a los yaganes, y que se pueda "colonizar algo de la tierra que fue de ellos, fundarles una escuela y hacerlos más felices” (p. 123). Cándido final en una novela que tiene su mayor fuerza precisamente en los momentos tormentosos y trágicos del drama natural.

\section{Conclusiones}

Estos cinco viajes poéticos, como se ha intentado mostrar, imaginan la conquista de lo desconocido antártico, primero como algo heroico y fascinante, para desembocar pronto, por la trasgresión y la desmesura, en una catábasis que puede llevar a la condena, la locura o la muerte. Son todos viajes trascendentales, donde la naturaleza se muestra como fuerza insurgente (Andermann, 2018, p. 
176), predominando el "drama natural, [...] el drama del hombre frente al mundo (Bachelard, 2017, p. 136), por sobre los conflictos entre humanos. En ese viaje a lo salvaje y desconocido el héroe retorna, a pesar de la tragedia, o por ella misma, con nuevos conocimientos a su lugar de origen. Estos libros juegan con ser testimonio de ello.

El viaje a la Antártida, como último territorio de la superficie de la Tierra por conocer, funciona como metáfora del propio conocimiento, de sus potencialidades y límites. ¿Es posible o recomendable rasgar el velo de Isis e intentar develar todo misterio? Prometeo, Ícaro y Orfeo son arquetipos mitológicos que se actualizan en estos textos, en los que la ambición de conquista humana sobre la naturaleza o sus secretos (reservados a los dioses) conlleva un castigo, a veces mortal. Como dice W. H. Auden (s/f) en su poema "Llegada a la luna": "La hybris siempre termina mal".

El registro mítico de estos textos, que sugiere una inmanencia, tiene de igual modo, y como se ha anotado, su correlato histórico en la conquista de la Antártida como parte de las expansiones coloniales y en su actual derretimiento por el calentamiento global, fruto catastrófico del desarrollismo capitalista con sus conocidos estragos sociales y ecológicos. Degradación planetaria que estos poemas y relatos de aventura, hybris y horror, con sus monstruos apocalípticos, con su "misticismo geográfico" (Reyes, 1997, p. 17), de algún modo vaticinan, como se ha trabajado aquí, actualizando mitología, poesía, ciencia, ecología y geopolítica, dando razón a la idea de ficción que desarrolla J-M. Schaeffer (2013): no como "imagen del mundo real", sino como "ejemplificación virtual de un ser-en-el-mundo posible" (p. 107), con la que podemos ejercitar respuestas al espacio y tiempo que nos toca.

\section{Referencias}

Agamben, G. (2016). Lo abierto. El hombre y el animal. Buenos Aires, Argentina: Adriana Hidalgo.

Andermann, J. (2018). Tierras en trance. Arte y naturaleza después del paisaje. Santiago, Chile: Ediciones Metales Pesados.

Argullol, R. (2008). Aventura. Una filosofía nómada. Barcelona, España: Acantilado.

Auden, W. H. (s/f) Llegada a la luna. Recuperado de: http://poesiatotal7.blogspot.com/2014/04/llegada-la-luna-de-w-h-auden.h tml, revisado el 27 de julio de 2020.

Bonnefoy, Y. (2010). Diccionario de mitologías. Barcelona, España: Backlist.

Borges, J. L. (1974). Obras completas 1923-1972. Buenos Aires, Argentina: Emecé. 
Bachelard, G. (2017). El derecho de soñar. México D.F., México: Fondo de Cultura Económica.

Biblia de Jerusalén (1976). Bilbao, España: Ed. Española Desclée de Brouwer.

Bloom, H. (2003). La compañía visionaria. Wordsworth, Coleridge, Keats. Buenos Aires, Argentina: Adriana Hidalgo.

Bunster, E. (1951). Mar del sur. Miniaturas históricas. Santiago, Chile: Nascimento.

Campbell, J. (2017). El héroe de las mil caras. Psicoanálisis del mito. México D.F., México: Fondo de Cultura Económica.

Castelli, E. (2007). Lo demoníaco en el arte. Su significado filosófico. Madrid, España: Siruela.

Catecismo de la Iglesia Católica (1997). Edición digital del Vaticano en http://www.vatican.va/archive/catechism sp/index sp.html

Chatwin, B. (1987). En la Patagonia. Barcelona, España: Muchnick Editores.

Coleridge, S.T. (2007). Balada del viejo marinero y otros poemas. Versión de J. María Martín Triana. Madrid, España: Visor.

Coloane, F. (1966). Los conquistadores de la Antártida. Santiago, Chile: Zig-Zag.

Descola, Ph. (2012). Más allá de naturaleza y cultura. Buenos Aires, Argentina: Amorrortu.

Díaz Solís, G. (1987). Introducción. En W. Wordsworth, W.; S.T. Coleridge. Baladas líricas y Biographia literaria. Caracas, Venezuela: Monte Ávila Editores.

Didi-Huberman, G. (2009). La imagen superviviente. Historia del arte y tiempo de los fantasmas según Aby Warburg. Madrid, España: Abada.

Estenssoro, F. (2014). Historia del debate ambiental en la política mundial 1945-1992. La perspectiva latinoamericana. Santiago, Chile: Instituto de Estudios Avanzados Universidad de Santiago de Chile.

Fernández-Armesto, F. (2012). Los conquistadores del horizonte. Una historia global de la exploración. Barcelona, España: Ariel.

Freud, S. (1994). El malestar en la cultura (1930). Obras Completas. Tomo XXI. Buenos Aires, Argentina: Editorial Amorrortu.

Grimal, P. (1989). Diccionario de mitología griega y romana. Buenos Aires, Argentina: Paidós. 
Heffes, G. (2014). "Introducción. Para una ecocrítica latinoamericana: entre la postulación de un ecocentrismo crítico y la crítica a un antropocentrismo hegemónico". Revista de Crítica Literaria Latinoamericana 79, pp.11-34.

Houellebecq, M. (2006). H.P. Lovecraft: contra el mundo, contra la vida. Barcelona, España: Siruela.

Jaeger, W. (1980). Paideia. México, D.F.: Fondo de Cultura Económica.

Lovecraft, H. P. (2017) En las montañas de la locura. Traducción de Calvert Casey. Barcelona, España: Seix Barral.

María, V. H. y Delgado, L. E. (1999) La Antártica. Santiago de Chile, Chile: Editorial Universitaria.

Mistral, G. (1978). Gabriela anda por el mundo. Santiago de Chile, Chile: Zig-Zag.

Morales, L. (2013). Ensayos. Santiago de Chile, Chile: Ediciones Universidad Diego Portales.

Morton, T. (2018). El pensamiento ecológico. Madrid, España: Paidos.

Naciones Unidas (1973). Informe de la conferencia de las Naciones Unidas sobre el medio humano. Estocolmo, 5 a 16 de junio de 1972. Recuperado de: https://www.dipublico.org/conferencias/mediohumano/A-CONF.48-14-RE V.1.pdf

Orrego V, E. (1948) Terra australis. Diario de la primera expedición Antártica Chilena. Santiago, Chile: Zig-Zag

Poe, E. A. (1962). Narraciones completas. Traducción de Julio Gómez de la Serna. Madrid, España: Aguilar.

Pratt, M. L. (2010). Ojos imperiales. Literaturas de viajes y transculturación. México, D.F.: Fondo de Cultura Económica.

Punter, D. y Byron, G. (2005). The Gothic. UK: Blackwell Publishing.

Rangel, Alberto. (2001) Inferno verde. Cenas e Cenários do Amazonas. Manaus, Brasil: Governo do Estado e Valer.

Reyes, A. (1997). La última Tule. Obras Completas 11. México D.F., México: Fondo de Cultura Económica.

Rivera, J. E. (1976). La vorágine. Santiago, Chile: Nascimento.

Rojas Mix, M. (2015). América imaginaria. Santiago, Chile: Pehuén. 
Rojo, G. (2009). Borges, Imperialismo y Colonialidad. ÍSTMICA. Revista De La Facultad De Filosofía y Letras, (11), pp.7-33. Recuperado de: https://www.revistas.una.ac.cr/index.php/istmica/article/view/388.

Rueda, M. H. (2003). La selva en las novelas de la selva. Revista de Crítica Literaria Latinoamericana, 29 (57), pp. 31-43

Serrano, M. (1948) La Antártica y otros mitos. Santiago, Chile: El Esfuerzo.

Serrano, M. (1957) Quién llama en los hielos. Santiago, Chile: Nascimento.

Serres, M. (2004). El contrato natural. Valencia, España: Pre-Textos.

Schaeffer, J.-M. (2009). El fin de la excepción humana. México D.F, México: Fondo de Cultura Económica.

Schaeffer, J. -M. (2013). Pequeña ecología de los estudios literarios. ¿Por qué y cómo estudiar la literatura? México D.F, México: Fondo de Cultura Económica.

Smith, C. (2019). Tierra y mar. Una reflexión sobre la historia universal. Madrid, España: Trotta.

Verne, J. (2011). La esfinge de los hielos. Madrid, España: Akal.

Vitale, I. (2019). De plantas y animales. Barcelona, España: Tusquets.

Wordsworth, W. y Coleridge, S. T. (1987) Baladas líricas y Biographia literaria.

(Selección, introducción y traducción de Gustavo Díaz Solís). Caracas,

Venezuela: Monte Ávila Editores.

Wordsworth, W. y Coleridge. S.T. (1994) Baladas líricas. (Edición bilingüe de Santiago Corugedo y José Luis Chamosa). Madrid, España: Cátedra. 